\title{
Combining Color and Morphology to Detect Low-Grade Urothelial Cell Carcinoma in Urine Specimens
}

\author{
Glickman $\mathrm{Y}^{1}$, Davis $\mathbb{N}^{1}$ and Nativ $\mathrm{O}^{2}$ \\ ${ }^{1}$ Micromedic Technologies Ltd., Tel Aviv, Israel \\ ${ }^{2}$ Department of Urology, Bnai Zion Medical Center, Haifa, Israel
}

Corresponding author: Yael Glickman, Micromedic Technologies Ltd., Tel Aviv, Israel, Tel: +972-732753450; E-mail: yael@m-medic.com

Received: 26 December 2016; Accepted: 30 December 2016; Published: 31 December 2016

Citation: Glickman Y, Davis N, Nativ O. Combining Color and Morphology to Detect Low-Grade Urothelial Cell Carcinoma in Urine Specimens. Arch Can Res. 2016, 4: 4.

\section{Brief Report}

Urine cytology is the most commonly used non-invasive test for the detection of urothelial cell carcinoma (UCC) [1]. While particularly valuable for the diagnosis of high-grade tumors, its clinical usefulness is often compromised by its reduced ability to detect low-grade tumors [2]. This low sensitivity, estimated at around $17 \%$ [3], is often explained by the lack of significant differences between the cytomorphological features of lowgrade cancer cells and benign reactive conditions [4]. Since $70 \%$ of non-muscle invasive bladder cancers are of low-grade, there is a real quest for a complementary urinary marker able to provide adjunctive non-cytomorphological information for the more accurate detection of low-grade urothelial carcinoma in urine specimens [5].

Several tests have been developed in recent years to complement standard cytology. Among these tests, two cellbased assays are of particular interest, because they permit the visualization of cancer cells. These markers include a multitarget fluorescent in situ hybridization (FISH) assay (UroVysion, Vysis/Abbott) based on the detection of chromosomal abnormalities in urothelial cancers, and an immunocytology test (ImmunoCyt/uCyt+, Diagnocure) based on the detection of the mucin-like antigens and high molecular form of carcinoembryonic antigen (CEA) expressed in most bladder cancer cells [6]. While these tests may help clinicians detect urothelial tumor recurrence $[7,8]$, they are both timeconsuming and require expensive dedicated equipment including special settings for fluorescent microscopy [5].

To address these drawbacks, a new histochemical stain (CellDetect, Zetiq Technologies) has been recently developed. Applying standard cytology equipment and following a simple staining protocol, the technique uses both color and morphology in order to distinguish between normal and malignant cells in one single urine specimen. Using bright field microscopy, this new cell-based marker highlights suspicious cells in red-purple (Figure 1), identifying malignant cells at a very early stage, even before they present the morphological traits of malignancy. The discriminative capacity of the stain, assumingly related to the increased metabolic activity inherent in cancer cells, has been shown to achieve $78 \%$ sensitivity for low-grade tumors in patients under routine surveillance [9].
This is particularly promising in the context of recent findings showing limitations of urine markers to correctly diagnose recurrent tumors presumably because of their small size [10].

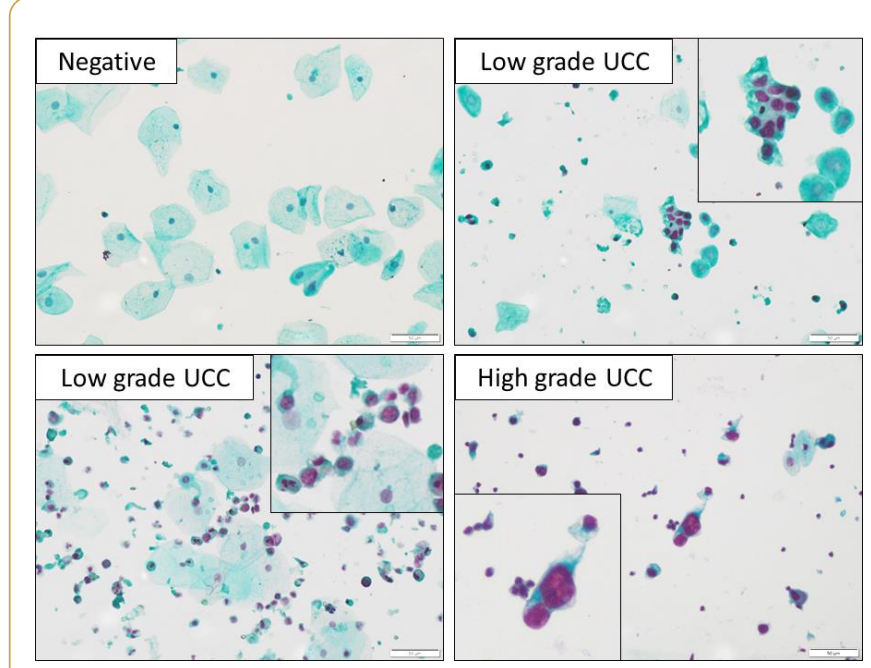

Figure 1 Photomicrographs of urine cytocentrifuge smears stained with Cell-Detect. Upper left: Negative case, upper right and lower left: Biopsy-confirmed low grade urothelial cell carcinoma (UCC), lower right: biopsy-confirmed high grade UCC. Epithelial cells are stained in green. Cases of UCC show dysplastic cells exhibiting reddish-purple nuclei (digital zoom in the boxes). Magnification: $x 40$, bar $=50 \mu \mathrm{m}$.

\section{References}

1. Yafi FA, Brimo F, Steinberg J, Aprikian AG, Tanguay S, et al. (2015) Prospective analysis of sensitivity and specificity of urinary cytology and other urinary biomarkers for bladder cancer. Urol Oncol 33: 25-31.

2. Babjuk M, Böhle A, Burger M, Capoun O, Cohen D, et al. (2016) EAU Guidelines on non-muscle-invasive urothelial carcinoma of the bladder: Update 2016. Eur Urol.

3. Van Rhijn B, Van Der Poel H, Van Der Kwast TH (2009) Cytology and urinary markers for the diagnosis of bladder cancer. Eur Urol Suppl 8: 536-541.

4. McCroskey Z, Kliethermes S, Bahar B, Barkan G, Pabuccian S, et al. (2015) Is a consistent cytologic diagnosis of low-grade 
urothelial carcinoma in instrumented urinary tract cytologic specimens possible? J Am Soc Cytopathol 4: 90-97.

5. Têtu B (2009) Diagnosis of urothelial carcinoma from urine. Modern Pathology 22: 53-59.

6. Xylinas E, Kluth LA, Rieken M, Karakiewicz PI, Lotan Y, et al. (2014) Urine markers for detection and surveillance of bladder cancer. Urol Oncol: Semin Orig Invest 32: 222-229.

7. Piaton E, Daniel L, Verriele V, Dalifard I, Zimmermann U, et al. (2003) Improved detection of urothelial carcinomas with fluorescence immunocytochemistry (uCyt+ assay) and urinary cytology: results of a French prospective multicenter study. Lab Invest 83: 845-852.
8. Gofrit ON, Zorn KC, Silvestre J, Shalhav AL, Zagaja GP, et al. (2008) The predictive value of multi-targeted fluorescent in-situ hybridization in patients with history of bladder cancer. Urol Oncol 26: 246-249.

9. Davis N, Shtabsky A, Lew S, Rona R, Leibovitch I, et al. (2016) A novel urine-based assay for bladder cancer diagnosis: Multiinstitutional validation study. Eur Urol Focus. In Press.

10. Schmitz-Dräger C, Bonberg N, Pesch B, Todenhöfer T, Sahin S, et al. (2016) Replacing cystoscopy by urine markers in the followup of patients with low-risk non-muscle-invasive bladder cancer? An International Bladder Cancer Network project. Urol Oncol 34: 452-459. 